\title{
Health profile with body mass index and physical fitness in Swedish adolescents: a cross-sectional study
}

https://doi.org/10.1515/ijamh-2020-0169

Received May 6, 2020; accepted July 19, 2020;

published online August 24, 2020

\section{Abstract}

Objectives: Physical inactivity and poor physical fitness in children and adolescents are growing public health problems globally. This study aimed to investigate the correlation between Body Mass Index (BMI) and three physical fitness components, including overall fitness, according to the Swedish Physical power, Mental harmony and Social capacity profile (FMS profile). Another aim was to investigate the test-retest reliability of the FMS questionnaire and fitness tests.

Methods: A total of 3,692 male and female adolescents in Sweden, between year 2004 and 2013, aged from 16 to 18 years old, were included. Height and weight data were collected to calculate the Body mass index (BMI). The participants performed physical fitness tests, which measure cardio-respiratory fitness, muscular strength and flexibility. The test-retest study included 18 adolescents, aged 16. They answered the FMS questionnaire and participated in the fitness tests with one-week interval.

Results: A weak inverse relationship between BMI and physical fitness was found: $r=-0.06$ to $-0.07(p<0.05)$ for flexibility, $r=-0.13$ to $0.10(\mathrm{p}<0.001)$ for strength, $r=-0.14$ to $-0.33(\mathrm{p}<0.001)$ for cardiorespiratory fitness, and $r=-0.15$ to $-0.27(p<0.001)$ for overall fitness. In the testretest study, the ICC's for strength, flexibility and balance were $0.94,0.96$ and 0.89 , respectively. The ICC's for the questions regarding lifestyle ranged from 0.75 to 1.00 and

*Corresponding author: Marie Alricsson, Professor, Ph.D., RPT, Department of Sports Science, Linnaeus University, Kalmar, SE-391 82, Sweden, Phone: +46 (0)73 8012299,

E-mail: marie.alricsson@lnu.se. https://orcid.org/0000-0001-6653-3414

Helen Yohannes, Department of Biosciences and nutrition, Karolinska Institutet, NOVUM, Huddinge, Sweden

Anna Hafsteinsson Östenberg, Department of Sports Science, Linnaeus University, Växjö, Sweden. https://orcid.org/0000-0001-5904-4428 for diet, physical activity and drugs were $0.56,0.44$ and 0.58 , respectively. The correlation was stronger in overweight/obese individuals compared to normal weight individuals.

Conclusion: Overweight and obese individuals scored lower in the fitness tests compared to their normal weight counterparts. The test-retest study revealed that the FMS questionnaire and fitness tests are reliable tools.

Keywords: BMI; cardiorespiratory fitness; epidemiology; flexibility; muscular strength; reliability; validity.

\section{Introduction}

Physical inactivity and poor physical fitness in children and adolescents are growing public health problems globally [1]. Physical fitness has been defined as "a set of attributes one has or achieves that relates to the ability to perform physical activity". There are various components that contribute to one's physical fitness. The health-related components include body composition (frequently expressed as body mass index, $\mathrm{kg} / \mathrm{m}^{2}$ ), aerobic fitness (also known as cardiorespiratory fitness), muscular strength and endurance and flexibility [2]. Although physical activity and physical fitness are often used interchangeably, they are not the same. However, both provide beneficial health outcomes and they are related. Gender, age, genetics and health status are all determinants of physical fitness. However, the main controllable and modifiable determinant is physical activity habits and/or pattern [3, 4]. Cardiorespiratory fitness is commonly used to measure habitual physical activity. It is defined as the ability of the circulatory and respiratory system to supply oxygen to the working muscles during sustained exercise. Cardiorespiratory fitness, which is generally quantified as maximal oxygen uptake $\left(\mathrm{VO}_{2} \max \right)$ is a reliable and low-cost measure that not only measures habitual physical activity, but it is also a valuable indicator of health [5]. Muscular strength is also an essential part of physical fitness which is when a muscle or a muscle group, in one single contraction, generates the 
maximum force [6]. Muscular strength has been shown to provide health benefits, not only for adults but also for youths. Evidence suggests that strength training may aid in weight loss and weight control through which the resting metabolic rate increases as a result thereof. Strength training may also improve bone mineralization, which in turn can prevent injuries from sports. Although peak bone mass is mainly influenced by genetics, increased bone mineral density resulting from strength training is also necessary for young girls who are at increased risk of developing osteopenia and/ or osteoporosis [7]. One's flexibility, which is also included as a component in physical fitness, may be enhanced through stretching exercises. It is believed that flexibility or hyper flexibility may increase the risk of injury while performing sports $[8,9]$. In other words, moderate flexibility is preferable.

Physical power, Mental harmony and Social capacity (FMS) student profile is a tool designed by the Swedish Institute Physical Mental Social $\mathrm{AB}$ for adolescents between the ages of 12 and 19 years old [10]. FMS student profile assesses teenagers' physical, mental and social health. The purpose of developing an assessment method as such was to enable individuals to take part of their own information associated with the person's lifestyle, health and well-being [10].

Hitherto, no evidence has been found on how Body mass index (BMI) affects physical fitness. A recent study with field test, for Latin-American adolescents, showed worse cardiorespiratory fitness in the obese group than their healthy counterparts, independent of anthropometric parameters [11]. Another study by Reid et al. [12] reported that tests of lower body power, body mass and fat percentage provide limited information concerning physical activity. Furthermore, a study by Xu et al. [13] showed a nonlinear relationship between weight status and physical fitness, and adolescents who were classified as underweight or obese had poorer physical fitness than their normal-weight peers.

Engaging in habitual physical activity, including cardio, strength and flexibility training, early on in adolescence is therefore important for achieving a good physical fitness, which may even possibly halt the increasing trends in overweight and obesity among adolescents worldwide.

Therefore, the aim of the present study was to investigate the correlation between BMI and three physical fitness components, including overall fitness, according to the Swedish FMS profile. Another aim was to investigate test-retest reliability of the FMS questionnaire and fitness tests.

\section{Materials and methods}

\section{Study design and participants}

This cross-sectional study analysed data from a sample of Swedish adolescents. The data, which was a part of the FMS student profile assessment, were collected during 2004 until 2013. High schools from three regions in the middle and south of Sweden ( $\mathrm{n}=19,660$ adolescents) were invited to participate in the present project. Approximately, three classes from each of the 45 high schools were available for different tests on the planned date and accepted the invitation $(n=4,550)$. All adolescents with valid data for gender, age, height and weight were included. Participants with no data from the cardiorespiratory fitness, muscular strength and endurance or flexibility tests were excluded. The final sample was therefore composed of 3,692 adolescents (2,173 boys; 59\% and 1,519 girls; 41\%). Parents/guardians and the participants were all informed about the nature and the procedure of the FMS questionnaire and the fitness tests. Signed consent forms by the parents/guardians and the students' agreement to participate were included.

The present investigation was conducted in accordance with the Declaration of Helsinki for human studies, and was approved by the Swedish Ethical Review Authority (Dnr 2019-05076).

\section{Measurements}

The FMS profile includes a questionnaire and fitness tests as well as anthropometric measurements (height and weight), which were conducted by school nurses.

Questionnaire: The different variables that assess physical, mental and social health, which are included in the FMS questionnaire are given below [10].

- Leisure activities: Examples of leisure activities include hobbies, friends, sports, reading, etc.

- Perceived stress: The former question on stress has been renamed life tempo in this questionnaire. This was done in order to make the student be more aware of how stress and feelings of calmness affect one's life in general. However, stress is specifically addressed again, towards the end of the questionnaire, but only concerning stress during the school day. The question about life tempo is subdivided into the frequency of being 'pressured and shattered' and 'calm and gathered' at school and/or during leisure time.

- Physical activity: The question asks about the frequency of physical activity. It is subdivided into a minimum of $20 \mathrm{~min}$ of planned 'physical conditioning enhancing exercise', which involves at least 12 (moderate intensity level) on the Borg scale [14] of perceived exertion, and 'daily exercise of $60 \mathrm{~min}$ which requires energy expenditure'. The latter includes both physical conditioning enhancing exercise and, for example, walking, skateboarding, gardening and school sports.

- Perceived health: This refers to both psychological and physical well-being. An adolescent can perceive his or her general wellbeing as "bad" due to various reasons such as having pimples, not having a girl/boyfriend, being too fat or too thin and complexes. The question is subdivided into: 'general well-being' 
referring to perceived health, 'symptoms of pain in neck, shoulder and back', 'headaches and/or stomach pain' and 'perceived fatigue'.

- Tobacco and alcohol use: In FMS, everything except "never smoked" or "never snuffed" has been approved as a health factor. This means that adolescents that smoke or use snuff only "occasionally at parties" have tobacco use as a risk factor. The number of cigarettes has been quantified per day, whereas the number of snuffboxes used per week was recorded. Frequency of alcohol consumed per month, including "rarely" and "never drink" was also used in the questionnaire.

- Diet: The question about diet has been subdivided into frequency of 'regular healthy eating habits' and 'intakes of candy, soda, crisp, cookies, etc.'. FMS herein defines regular healthy eating habits as consuming breakfast, lunch, dinner and snack (Sandwich or fruit, for example) every day. These meals ought to include sufficient amounts of carbohydrates (pasta, potatoes, rice, bread and nuts); protein (chicken, meat, fish, beans and lentils); and vitamins and minerals (fruits and vegetables). In addition, intakes of these nutrients should not be over- or under consumed. Intakes of candy, soda, crisp, cookies, etc. have been defined as intakes of unhealthy foods.

- Sleep: This question is subdivided into: 'sleep onset time', 'number of sleeping hours' and 'quality of sleep'.

Fitness tests: All the fitness tests took place during physical education (PE) sessions conducted by PE teachers, according to standardised protocols. The PE teachers had been provided with detailed information and demonstrations of the fitness tests prior to testing. The maximal oxygen uptake $\left(\mathrm{VO}_{2} \max \right)$ was measured using the Cooper test. The Cooper test includes warm-up and then running either 2.4, 3 or $3.4 \mathrm{~km}$ at a steady pace, depending on how well trained the participants perceived themselves. The weight in kilograms of each participant, pulse and the time they finished were recorded and $\mathrm{VO}_{2}$ max calculated. The Cooper test has been validated elsewhere [15], and its correlation factor to a laboratory test (treadmill) is extremely high, 0.897. For students not exercising regularly, however, results obtained from so-called maximal test can be misleading since they may not push themselves to the maximum. Therefore, submaximal tests such as 1MileWalktest, Step test or Åstrand cycle ergometer test were used instead to measure $\mathrm{VO}_{2}$ max. The 1 MileWalktest's distance is $1,609 \mathrm{~m}$, and the participants are instructed to walk as fast as possible without running or jogging. The test has been validated previously [16] while walking on a treadmill and the correlation factor was 0.84 . The Step test, which has been validated [17, 18], involves stepping up and down a 40 or $33 \mathrm{~cm}$ bench, depending on how well trained one is, for $5 \mathrm{~min}$ at a rate of 90 steps per minute. The heart rate is measured from 15 to $30 \mathrm{~s}$ after completing the test. The Borg Scale [14] is used every now and then during the test and following completion of the test, it ought to land at 12; otherwise, the results obtained are not reliable and cannot be used. In the cycle ergometer test, the resistance is set and the rate is defined. Heart rate is measured every minute, and the Borg scale is used here as well. The test has also been validated previously [19], and the obtained correlation factor was 0.76 .

To measure muscular strength and endurance, a metronome was used in order to standardise the pace of the movements in each strength test. Sit-ups, arm lift ( $5 \mathrm{~kg}$ for females, 5 or $10 \mathrm{~kg}$ for males), sitting chair for as long as possible and the belly back test (back extensions/lift) were the strength tests included. An overall strength index from one (very weak) to five (very strong) was thereafter calculated from the average of the four tests.

The flexibility tests were carried out following warm-up. Shoulder, neck, back, chest and pelvis stretches were included. Again, the average of those gave an overall flexibility index/score from one to five; ( 1 = six or more exercises needed to stretch, 2 = five of the exercises needed to stretch, $3=$ three or four exercises needed to stretch, $4=$ two of the exercises needed to stretch, $5=$ all exercises are good).

\section{Relative validity}

Relative validity was used for three of the variables (tobacco use, alcohol and diet). The results obtained in our study were compared with data from previous surveys that have validated these three particular questions [20]. Therefore, only these three parameters were used, and relative validation could therefore only be done for these three variables and not the other questions in the questionnaire. After filling out the questionnaire, participants were asked how they perceived the questions and what they thought when they responded to the questions.

\section{Test-retest reliability}

In the test-retest reliability, 18 adolescents aged 16 years old (11 males and 7 females) from a high school in Sweden were asked to fill in the questionnaire and complete the fitness tests with one week interval. Only the fitness tests for muscular strength and endurance as well as for flexibility were completed but not for cardiorespiratory fitness. Since there is abundance of validation studies on the tests used for measuring cardiorespiratory fitness, it was not necessary to include it in the reliability study.

\section{Statistical analysis}

Statistical analyses were performed using IBM SPSS Statistics for Windows v.22.0 (SPSS, New York, USA). Descriptive data were presented as mean and standard deviation, and the average weight and height in all age groups were calculated as well. Age- and gender adjusted international cut-off points, according to Cole et al. (2000) and Cole et al. (2007) [21, 22], were used to classify the participants as underweight, normal weight, overweight or obese.

Student independent t-test was used to test differences in physiological and physical characteristics between normal weight and overweight/obese participants. Pearson's moment correlation coefficient (r) was used to examine the association between physical fitness and BMI in all subjects as well as in normal weight and overweight/obese subjects. Moreover, an overall fitness score from one (very weak) to five (very strong) was included by calculating the mean from standardised $\mathrm{VO}_{2}$ max values, flexibility and strength scores.

In the reliability study, intra-class correlation coefficient (ICC) with $95 \%$ confidence intervals (CI) was used for test-retest. Significance level was set at $\alpha=0.05$. 


\section{Results}

\section{Relative validity}

The results obtained from the males and females answering the FMS questionnaire regarding tobacco use, alcohol and diet were compared with data from previous surveys that have validated these three particular questions [20]. Since the results in FMS and the data from the surveys were reasonably similar, it was concluded that there is a relative validity to these three questions.

\section{Test-retest reliability}

A total of 18 (11 males, 7 females) 16 year old ninth graders participated in the test-retest study. The ICCs for strength, flexibility and balance were 0.94, 0.96 and 0.89, respectively. This indicates an almost perfect agreement between the two test trials. The ICCs for the questions regarding lifestyle ranged from 0.75 to 1.00 , indicating substantial to perfect agreement except for diet, physical activity and drugs (ICC $=0.56,0.44$ and 0.58 , respectively), which had lower ICCs. Questions concerning psychological health and somatic pain had ICCs ranging from 0.64 to 0.88 , demonstrating a substantial to almost perfect agreement. The ICCs for perceived health and stress were however lower (ICC $=0.23$ and 0.60 , respectively). The school environment and relationship questions had ICCs ranging from 0.61 to 0.95, showing a considerable to almost perfect agreement.

\section{Characteristics of the study sample}

A total of 3,692 subjects (59\% males and 41\% females), with a mean age of 17.5 years old participated in the study. The prevalence of overweight/obesity amongst the males was $23.7 \%$, while it was less amongst the females, $15.3 \%$ (Table 1).

Descriptive statistics with comparisons of physiological and physical parameters between normal weight and overweight/obese subjects are presented in Table 1. With regard to the fitness parameters (strength, flexibility and $\mathrm{VO}_{2}$ max), there were significant differences between normal and overweight/obese males and females, $p<0.001$ (except in flexibility among the females, $\mathrm{p}<0.05$ ) (Table 1).

\section{BMI and fitness}

The fitness parameters and BMI amongst all the females were weakly negatively correlated. Similarly, the same was found amongst all the males. However, the negative inverse correlation was stronger in males, mainly in $\mathrm{VO}_{2}$ max and overall fitness (Table 2). BMI and all the fitness parameters were weakly negatively associated in overweight/ obese females. BMI and overall fitness also had a weak inverse correlation. No relationship was observed between BMI and the fitness measures, or overall fitness, in normal weight individuals. Likewise, weak negative inverse association between BMI and all of the fitness measures was also found amongst the overweight/obese males. However, almost no relationship was found in normal weight subjects (Table 3).

With regard to overall fitness score and BMI categories, there was a higher proportion of normal weight participants that had an overall fitness score of three $(46.4 \%$ of the males and $45.5 \%$ of the females) and four (17.3\% of the males and $13.8 \%$ of the females). On the other hand, the overweight/obese participants had the highest percentage of individuals within one $(14.3 \%$ of the males and $12.8 \%$ of the females) and two (48.8\% of the males and $47.2 \%$ of the females) of overall fitness score.

Table 1: Descriptive statistics with comparisons of physiological and physical parameters between normal weight and overweight/obese for females and males respectively.

\begin{tabular}{|c|c|c|c|c|}
\hline \multirow[t]{2}{*}{ Variables } & \multicolumn{2}{|r|}{ Females } & \multicolumn{2}{|r|}{ Males } \\
\hline & $\begin{array}{r}\text { Normal weight } \\
\text { Mean } \pm \text { SD }(n=1,275)\end{array}$ & $\begin{array}{r}\text { Overweight/Obese } \\
\text { Mean } \pm \text { SD }(n=244)\end{array}$ & $\begin{array}{r}\text { Normal weight } \\
\text { Mean } \pm \text { SD }(n=1,633)\end{array}$ & $\begin{array}{l}\text { Overweight/Obese } \\
\text { Mean } \pm \text { SD }(n=540)\end{array}$ \\
\hline Age & $17.5 \pm 0.3$ & $17.5 \pm 0.3$ & $17.5 \pm 0.3$ & $17.5 \pm 0.3$ \\
\hline Height $(\mathrm{cm})$ & $166.9 \pm 6.4$ & $166.3 \pm 6.8$ & $179.2 \pm 7.2$ & $180.0 \pm 6.4^{\star}$ \\
\hline Weight (kg) & $58.6 \pm 6.8$ & $75.3 \pm 9.3^{\star \star \star}$ & $67.8 \pm 7.9$ & $91.1 \pm 13.2^{\star \star \star}$ \\
\hline BMI $\left(\mathrm{kg} / \mathrm{m}^{2}\right)$ & $21.0 \pm 1.9$ & $27.2 \pm 2.6^{\star \star \star}$ & $21.1 \pm 1.8$ & $28.1 \pm 3.4^{\star \star \star}$ \\
\hline Flexibility & $3.3 \pm 1.6$ & $3.0 \pm 1.5^{\star}$ & $3.1 \pm 1.5$ & $2.8 \pm 1.5^{\star \star \star}$ \\
\hline Strength & $3.3 \pm 0.9$ & $3.0 \pm 0.9^{\star \star \star}$ & $3.1 \pm 0.9$ & $2.8 \pm 0.8^{\star \star \star}$ \\
\hline $\mathrm{VO}_{2} \max (\mathrm{mL} / \mathrm{min} / \mathrm{kg})$ & $37.7 \pm 8.2$ & $34.8 \pm 8.6^{\star \star \star}$ & $45.9 \pm 9.9$ & $38.3 \pm 8.8^{\star \star \star}$ \\
\hline
\end{tabular}

${ }^{\star}=p<0.05,{ }^{\star \star *}=p<0.001$. 
Table 2: Correlation (Pearson coefficient $r$ ) between BMI and fitness parameters of the study group. Females $n=1,519$ and males $n=2,173$

\begin{tabular}{lrr}
\hline Variables & & BMI \\
\cline { 2 - 3 } & Females & Males \\
\hline Flexibility & $-0.07^{\star}$ & $-0.06^{\star}$ \\
Strength & $0.10^{\star \star \star}$ & $-0.13^{\star \star \star}$ \\
$\mathrm{VO}_{2}$ max $(\mathrm{mL} / \mathrm{min} / \mathrm{kg})$ & $-0.14^{\star \star \star}$ & $-0.33^{\star \star \star}$ \\
Overall fitness & $-0.15^{\star \star \star}$ & $-0.27^{\star \star \star}$ \\
\hline
\end{tabular}

${ }^{*}=p<0.05,{ }^{* \star *}=p<0.001$.

Table 3: Correlation (Pearson coefficient $r$ ) between BMI and fitness parameters in normal weight and in overweight/obese of the study group, $(n=3,692)$.

\begin{tabular}{|c|c|c|c|c|}
\hline \multirow[t]{2}{*}{ Variables } & \multicolumn{2}{|r|}{ Females } & \multicolumn{2}{|r|}{ Males } \\
\hline & $\begin{array}{r}\text { Normal } \\
\text { weight } \\
\text { BMI }\end{array}$ & $\begin{array}{r}\text { Overweight/ } \\
\text { Obese BMI }\end{array}$ & $\begin{array}{r}\text { Normal } \\
\text { weight } \\
\text { BMI }\end{array}$ & $\begin{array}{r}\text { Overweight/ } \\
\text { Obese BMI }\end{array}$ \\
\hline Flexibility & -0.01 & $-0.16^{\star}$ & 0.03 & -0.04 \\
\hline Strength & $0.06^{\star}$ & $-0.27^{\star \star \star}$ & $0.16^{\star \star \star}$ & $-0.28^{\star \star \star}$ \\
\hline $\begin{array}{l}\mathrm{VO}_{2} \max \\
\quad(\mathrm{mL} / \mathrm{min} / \\
\mathrm{kg})\end{array}$ & -0.04 & $-0.16^{\star}$ & 0.01 & $-0.40^{\star \star \star}$ \\
\hline $\begin{array}{l}\text { Overall } \\
\text { fitness }\end{array}$ & -0.00 & $-0.31^{\star \star \star}$ & $0.09^{\star \star \star}$ & $-0.33^{\star * \star}$ \\
\hline
\end{tabular}

\section{Tobacco and alcohol use}

The data showed that cigarette use was more common than snuffing. The majority of the 16 to 18 years old participants in FMS were non-smokers $(66.7 \%$ of the males and $77.2 \%$ of the females) while $75 \%$ of the males and $94 \%$ of the girls did not use snuff. Furthermore, in FMS, the proportion of alcohol consumers was 66.3 and $65.6 \%$ in the males and females, respectively.

\section{Discussion}

The main finding in the present cross-sectional study of a weak inverse association between BMI and fitness was found amongst all the females and males. The negative inverse association was more strongly correlated when normal weight and overweight/obese girls, and boys were separated. Lowest fitness scores were observed amongst boys and girls with the highest BMI (overweight/obese). The correlation between BMI and fitness was predominantly noticeable in $\mathrm{VO}_{2}$ max and overall fitness, especially amongst the boys. These findings support the notion that normal weight adolescents are more likely to have higher physical fitness than overweight/obese individuals, which is also in agreement with previous studies [23-28]. However, these studies [23-28] only examined cardiorespiratory fitness $\left(\mathrm{VO}_{2} \max \right)$ and its association with $\mathrm{BMI}$, and they did not take into account strength or flexibility, which are both important components of overall physical fitness. Braitwaite et al. reported that physical activity is not associated with lower BMI among children and adolescents. They stated that physical activity and BMI may be best undertaken in conjunction with other variables in the energy expenditure [29]. Nevertheless, Chen et al., Zar et al. and Joshi et al. did look at fitness tests measuring strength and flexibility [23, 24, 28]. These studies also found that normal weight individuals scored higher in, not only fitness test measuring cardiorespiratory fitness but also in strength and flexibility tests. However, overweight participants either performed as good as their normal weight counterparts or not far from it in the strength tests. Therefore, although in our study the participants with lower BMIs were more likely to achieve a higher overall fitness score compared to those with higher BMIs, it should still be noted that a proportion of overweight/obese subjects did score a three or four in overall fitness. Similarly, a few of the normal weight participants scored one or two in overall fitness. In other words, an individual categorised as overweight/obese according to BMI can still be physically fit due to the person's muscle mass. Conversely, a person categorised as normal weight can have poor physical fitness as a result of low muscle mass. Thus, BMI as a tool is not always optimal. Nevertheless, it is not completely correct to draw such conclusions that they seem to be a representative group just by looking at height. If data on the students' parents' educational level, ethnicity or socioeconomic status were available, it could have given a better picture of whether or not they are a representative sample.

The test-retest study revealed that the FMS questionnaire, which measures physical, social and mental health in adolescents, is a reliable tool to use. Almost perfect testretest reliability was found for strength, flexibility and balance. The reliability for the parameters concerning lifestyle showed moderate to perfect agreement. Questions regarding psychological health and somatic pain as well as school environment and relationship showed substantial to almost perfect test-retest reliability. Nevertheless, stress, perceived health, diet, physical activity and drugs had low ICC values between the two test trials. When measuring a person's perceived health or stress, it is expected to obtain moderate to good test-retest reliability. This is due to the 
fact that one's perceived health and stress are likely to change within short time periods [30], even within a week interval as in this case. Obtaining higher ICC values, which would be indicative of perfect agreement, would instead mean that the actual question being tested is not catching these changes. Measuring diet, physical activity and drugs is however usually not due to intra-individual variability and day-to-day changes. The obtained substantial to moderate agreement is most probably attributable to under-reporting regarding diet and drugs and overreporting in physical activity levels [31].

Measuring the validity of a questionnaire is difficult and it has several dimensions. However, in this study, the fitness tests used to measure cardiorespiratory fitness, i.e. $\mathrm{VO}_{2}$ max, have been validated elsewhere [15-19] against a criterion instrument such as a treadmill. All of the tests used in this study have shown to have a correlation factor ranging from 0.76 to 0.90 , indicating to be valid tests to measure cardiorespiratory fitness.

Being overweight and/or obese can lead to other diseases such as, for example, the metabolic syndrome (hypertension, hyperglycaemia, dyslipidaemia) [32-34]. All of these illnesses are in turn risk factors for cardiovascular disease (CVD) such as heart disease. The developing atherosclerotic process of heart disease starts early on in childhood and adolescence, and continues into adulthood if one or many of the risk factors are present [33-35]. Similarly, it has been proposed that low physical fitness is associated with the clustering of these CVD risk factors in Swedish adolescent males later in life [34]. Therefore, being overweight and/or obese along with having low physical fitness increases the risk of developing CVD later in life [35].

Besides the physical consequences of being overweight and obese, there are psychosocial concerns as well. Adolescents who are overweight or obese often suffer from having low self-esteem, social isolation and having increased risk of developing depression. In addition, when dealing with such a group as adolescents, it is important to not only try to solve the overweight and/or obese problem by increased physical activity and healthy eating, but it is also necessary to take into account the actual problem that may be the underlying cause of why an individual has become overweight or obese. In many cases, traumas of some kind, bullying or not thriving in school are examples of some underlying bases, which must be addressed as well [36].

By participating in the present study, the students have been given motivational talks with either an instructed nurse or PE teacher. The aim of this was to arouse the student's own thoughts of his/her own lifestyle behaviour and give advice on how to change it. The nurse/PE teacher has also followed some principles during the talk. These include supporting self-reliance, showing empathy, avoiding arguments and having a collaborative approach as well as showing to be an equal partner instead of patronising. The students have also been taught how to correctly perform strength and flexibility exercises by experienced PE teachers. Furthermore, participating in the FMS study does not really include any risks, except if the participants would injure themselves while carrying out any of the fitness tests; however, they had been informed about that prior to agreeing to participate.

Having a student profile, such as the one conducted by FMS, which assesses physical, social and mental health among adolescents is very important. This can help schools who decide to use the student profile to acquire an overview of the health among the students. Subsequently, the school can work on improving the health by implementing certain measures and interventions.

The strengths of this study were that the anthropometric measurements and the fitness tests were conducted by experienced nurses and PE teachers. All the equipment and the fitness tests were standardised. Additionally, the large sample size was also a strength in our study. Moreover, the fact that a test-retest study was included is also unique in the present study.

Although BMI is a useful tool to use in large populations, particularly among children and adolescents, solely using it alone to assert an association with physical fitness was a limitation. Instead, measurements of body fat and muscle mass (which were measured in our study, but only in a small number of individuals) ought to be used together with BMI. Also, physical activity pattern was measured in this study; however, it was only done in a very small proportion of the study population, which is a drawback. Physical fitness depends on genetics and other non-modifiable factors (age, gender, etc.). However, the foremost controllable factor is physical activity [3, 4]. Since data on PA habits were not complete in our study, its relative contribution cannot be determined. In addition, whether or not there is a correlation between the measured $\mathrm{VO}_{2}$ max and the amount of PA reported in the questionnaire cannot be asserted either. The fact that a number of students were excluded since data on weight and height were not available is also another limitation that could have influenced the results. Lastly, the crosssectional design of this study is also a limitation, given that it can only show an association and not causality. Therefore, the results ought to be considered with caution. However, it is rational to believe that adolescents with higher BMI values will also score lower in fitness tests. 


\section{Conclusions}

Physical fitness and BMI were weakly negatively associated. Overweight and obese individuals scored lower in the fitness tests compared to their normal weight counterparts. The test-retest study revealed that the FMS questionnaire and fitness tests are reliable tools.

In order to combat the increasing prevalence of overweight and obesity among adolescents, the promotion of physical activity in school settings has to be improved. Walking to and from school, increasing physical education time, and food and nutritional education are some suggestions.

Research funding: None declared.

Author contribution: All the authors have accepted responsibility for the entire content of this submitted manuscript and approved submission.

Competing interests: The authors declare no conflicts of interest regarding this article.

Informed consent: Informed consent was obtained from all individuals included in this study.

Ethical approval: The present investigation was conducted in accordance with the Declaration of Helsinki for human studies, and was approved by the Swedish Ethical Review Authority (Dnr 2019-05076).

\section{References}

1. WHO. New WHO-led study. Available online: https://www.who.int/ news-room/detail/22-11-2019-new-who-led-study-says-majorityof-adolescents-worldwide-are-not-sufficiently-physically-activeputting-their-current-and-future-health-at-risk [Accessed $14 \mathrm{Apr}$ 2020].

2. Caspersen CJ, Powell KE, Christenson GM. Physical activity, exercise, and physical fitness: definitions and distinctions for health-related research. Publ Health Rep 1985;100: 126-31.

3. Morrow JR, Jr., Tucker JS, Jackson AW, Martin SB, Greenleaf CA, Petrie TA. Meeting physical activity guidelines and health-related fitness in youth. Am J Prev Med 2013;44:439-44.

4. Thompson PD, Eijsvogels TMH. New physical activity guidelines: a call to activity for clinicians and patients. J Am Med Assoc 2018; 320:1983-4.

5. Lee DC, Artero EG, Sui X, Blair SN. Mortality trends in the general population: the importance of cardiorespiratory fitness. J Psychopharmacol 2010;24:27-35.

6. Micheo W, Baerga L, Miranda G. Basic principles regarding strength, flexibility, and stability exercises. Arch PM\&R (Phys Med Rehabil) 2012;4:805-11.

7. Faigenbaum AD. Strength training for children and adolescents. Clin Sports Med 2000;19:593-619.
8. Armstrong R, Greig DM. The Beighton score as a predictor of Brighton criteria in sport and dance. Phys Ther Sport 2018;32: 145-54.

9. Thacker SB, Gilchrist J, Stroup DF, Kimsey CD , Jr. The impact of stretching on sports injury risk: a systematic review of the literature. Med Sci Sports Exerc 2004;36:371-8.

10. Swedish Institute, Physical power, mental harmony and social capacity (FMS) student profile. [In Swedish]. Available online: https://fms.se/ [Accessed 15 Apr 2020].

11. Ramirez-Velez R, Garcia-Hermoso A, Alonso-Martinez AM, Agostinis-Sobrinho C, Correa-Bautista JE, Triana-Reina HR, et al. Cardiorespiratory fitness normative values in Latin-American adolescents: role of fatness parameters. Int J Environ Res Publ Health 2019;14:16.

12. Reid RER, Fillon A, Thivel D, Henderson M, Barnett TA, Bigras JJL, et al. Can anthropometry and physical fitness testing explain physical activity levels in children and adolescents with obesity?. J Sci Med Sport 2019;S1440-2440:31193-4.

13. Xu Y, Mei M, Wang H, Yan Q, He G. Association between weight status and physical fitness in Chinese Mainland children and adolescents: a cross-sectional study. Int J Environ Res Publ Health 2020;4:17.

14. Borg G. Perceived exertion as an indicator of somatic stress. Scand J Rehabil Med 1970;2:92-8.

15. Cooper KH. A means of assessing maximal oxygen intake. Correlation between field and treadmill testing. J Am Med Assoc 1968;203:201-4.

16. McSwegin PJ, Plowman SA, Wolff GM, Guttenberg GL. The validity of a one-mile walk test for high school age individuals. Meas Phys Educ Exerc Sci 1998;2:47-63.

17. Ryhming I. A modified Harvard step test for evaluation of physical fitness. Arbeitsphysiologie 1953;15:235-50.

18. Sharkey BJ. Physiological fitness and weight control. Missoula, Montana: Mountain Press Publishing Co; 1974.

19. Grant S, Corbett K, Amjad AM, Wilson J, Aitchison T. A comparison of methods of predicting maximum oxygen uptake. $\mathrm{Br} J$ Sports Med 1995;29:147-52.

20. Public Health Agency of Sweden. The national public health survey, 2006-2008. Sweden: Public Health Agency; 2009 [In Swedish].

21. Cole TJ, Bellizzi MC, Flegal KM, Dietz WH. Establishing a standard definition for child overweight and obesity worldwide: international survey. BMJ 2000;320:1240-3.

22. Cole TJ, Flegal KM, Nicholls D, Jackson AA. Body mass index cut offs to define thinness in children and adolescents: international survey. BMJ 2007;335:194.

23. Chen X, Cui J, Zhang Y, Peng W. The association between BMI and health-related physical fitness among Chinese college students: a cross-sectional study. BMC Publ Health 2020;20:444.

24. Zar A, Karan-Khosravi P, Ahmadi-Mohammad A. Prevalence of obesity and overweight among female students of Shiraz University of Medical Sciences and its association with physical fitness factors. Community Health 2017;4:79-89.

25. Huang YC, Malina RM. Body mass index and individual physical fitness tests in Taiwanese youth aged 9-18 years. Int J Pediatr Obes 2010;5:404-11.

26. Aires L, Silva P, Silva G, Santos MP, Ribeiro JC, Mota J. Intensity of physical activity, cardiorespiratory fitness, and body mass index in youth. J Phys Activ Health 2010;7:54-9. 
27. He QQ, Wong TW, Du L, Jiang ZQ, Yu TS, Qiu H, et al. Physical activity, cardiorespiratory fitness, and obesity among Chinese children. Prev Med 2011;52:109-13.

28. Joshi P, Bryan C, Howat H. Relationship of body mass index and fitness levels among schoolchildren. J Strength Condit Res 2012; 26:1006-14.

29. Braithwaite IE, Stewart AW, Hancox RJ, Murphy R, Wall CR, Beasley R, et al. ISAAC phase tree study group. Body mass index and vigorous physical activity in children and adolescents: an international cross sectional study. Acta Paediatr 2017;106: 1323-30.

30. King B, Berg L, Koenig J, Adair JJ, Tirado C. A revised occupational stress measure for popular musicians: pilot test of validity and reliability. Med Probl Perform Ar 2019;34:85-91.

31. Tomaz SA, Lambert EV, Karpul D, Kolbe-Alexander TL. Cardiovascular fitness is associated with bias between selfreported and objectively measured physical activity. Eur J Sport Sci 2016;16:149-57.
32. Rizzo AC, Goldberg TB, Silva CC, Kurokawa CS, Nunes HR, Corrente JE. Metabolic syndrome risk factors in overweight, obese, and extremely obese Brazilian adolescents. Nutr J 2013;12:19.

33. Ekelund U, Anderssen SA, Froberg K, Sardinha LB, Andersen LB, Brage S. European Youth Heart Study Group. Independent associations of physical activity and cardiorespiratory fitness with metabolic risk factors in children: the European youth heart study. Diabetologia 2007;50:1832-40.

34. Henriksson H, Henriksson P, Tynelius P, Ekstedt M, Berglind D, Labayen I, et al. Cardiorespiratory fitness, muscular strength, and obesity due to cardiovascular disease: a cohort study of I million men. Eur Heart J 2020;14:1503-10.

35. Umer A, Kelley GA, Cottrell LE, Giacobbi P, Jr., Innes KE, Lilly CL. Childhood obesity and adult cardiovascular disease risk factors: a systematic review. BMC Publ Health 2017;17:683.

36. Xie B, Ishibashi K, Lin C, Peterson DV, Susman EJ. Overweight trajectories and psychosocial adjustment among adolescents. Prev Med 2013;57:837-43. 